\title{
MISOGINIA NO TRAÇO: VIOLÊNCIA CONTRA AS MULHERES COMO PRETEXTO TEMÁTICO EM CHARGES
}

\author{
MISOGYNY IN THE TRAIT: VIOLENCE AGAINST WOMEN \\ AS THE THEMATIC PRETEXT IN EDITORIAL CARTOONS
}

\section{RESUMO}

Este artigo pretende refletir sobre o uso da violência contra mulheres como um pretexto temático utilizado como argumento visual na produção de charges. Entendemos que as charges consistem em uma modalidade do humor gráfico, produzido pelo traço humano, de natureza dissertativa. A charge, imbuída de crítica política e social, é construída retratando um determinado ponto de vista sobre um fato histórico por meio de recursos visuais. Produzida no contexto da sociedade patriarcal, pode reproduzir as relações de dominação e exploração a que as mulheres estão submetidas. Por meio da metodologia de análise do discurso chárgico, analisamos a presença de mulheres em charges que discutem temas como política, economia e sociedade, enfatizando o uso da violência contra a mulher - sobretudo, violência sexual - como um pretexto temático para construir a crítica na charge, que acaba contribuindo para a manutenção de estereótipos e da condição opressiva imposta sobre as mulheres.

Palavras-chave: Violência contra a mulher. Patriarcado. Charge. Humor gráfico.

\begin{abstract}
This article discusses the use of violence against women as a thematic pretext used as an visual argument in the production of editorial cartoons. We understand that editorial cartoons consist of a mode of graphic humor, produced by the human trait, of dissertative nature. The editorial cartoon, imbued with political and social criticism, is constructed by portraying a certain point of view on a historical fact through visual means. Produced in the patriarchal society, editorial cartoons can reproduce the relations of domination and exploitation to which women are subjected. Through the methodology of analysis of the cartoon discourse, we analyze the presence of women in editorial cartoons that discuss subjects like politics, economy and society, emphasizing the use of violence against the woman like a thematic pretext to construct the criticism in the editorial cartoon, which contributes to the maintenance of stereotypes and the oppressive condition imposed on women
\end{abstract}

Keywords: Violence against women. Patriarchy. Editorial cartoon. Graphic humor.

\footnotetext{
Alana N. Volpato

Universidade Estadual Paulista Júlio de Mesquita Filho / Campus Bauru (UNESP) - Brasil. E-mail: alanavolpato@gmail.com

Nayara A. Damião

Universidade Estadual de Londrina (UEL) - Brasil. E-mail: nayara.damiao@gmail.com

Rozinaldo A. Miani

Universidade Estadual de Londrina (UEL) - Brasil. E-mail: mianirozinaldo@gmail.com
} 


\section{Introdução}

Este artigo tem como objetivo abordar a utilização da violência contra mulheres como um pretexto temático em charges e cartuns que tratam de temas diversos, como sociedade, política ou economia. A necessidade de investigar essa abordagem na elaboração de charges se justifica por duas motivações principais. A primeira delas é a constatação de que a produção de charges para os veículos midiáticos, majoritariamente, é realizada por homens. Basta buscar nos principais jornais e revistas do país, independentemente da linha editorial, para perceber a ausência de mulheres como autoras de charges e cartuns publicados ${ }^{1}$.

A segunda motivação diz respeito à própria natureza da charge e do cartum que, de acordo com Rozinaldo Miani (2012), são modalidades do humor gráfico, constituída por imagens produzidas pelo traço humano, assim como a caricatura e as histórias em quadrinhos. As diferentes modalidades do humor gráfico são caracterizadas de acordo com sua natureza: histórias em quadrinhos são essencialmente narrativas; caricaturas (ou retratos caricatos) são predominantemente descritivas; charges e cartuns são de natureza dissertativa. Diante disso, podemos aferir que charges e cartuns vão além da apresentação de um fato ou assunto específicos; eles expressam sempre uma opinião sobre o episódio ou tema retratado, com a finalidade de realizar uma crítica.

Os cartuns apresentam uma crítica atemporal, constituindo uma imagem que pode fazer sentido para leitores fora do seu contexto temporal ou espacial de publicação. Por isso, cartuns não utilizam em sua composição gráfica retratos caricatos de pessoas específicas, mas sim personagens fictícios que permitem realizar uma crítica de hábitos e costumes.

Por sua vez, as charges representam uma opinião sobre pessoas e fatos específicos, exigindo do leitor algum conhecimento anterior sobre a situação exposta para que a mensagem faça sentido. O contexto sócio-histórico e de produção da charge constituem elementos fundamentais para sua compreensão. Na medida em que a situação retratada pela charge vai se distanciando da realidade social imediata, as inferências visuais deixam de ter sentido e o potencial comunicativo da charge se esgota. No entanto, reside aí o potencial como fonte histórica, por apontar fatos e interpretações presentes na memória social.

Essa é a razão pela qual voltamos nosso olhar para essas imagens, considerando que, por seu caráter histórico e de crítica política e cultural, bem como por sua relação com a memória social, os elementos visuais em charges e cartuns nos dão indícios da composição do imaginário social e de como as relações de dominação e de exploração das mulheres são reproduzidas no ambiente comunicativo.

1 Se, por um lado, não podemos esquecer de Hilde, uma das mais importantes chargistas que produziu durante décadas para diversos jornais e revistas no Brasil - Folha de S. Paulo, O Cruzeiro, Tribuna da Imprensa, O Estado de S. Paulo - e Ciça, com seus cartuns publicados na Folha de S. Paulo, por outro lado, não há muitas outras chargistas mulheres que tiveram oportunidade de ocupar esse espaço estratégico no contexto da produção midiática brasileira. 
Por meio da metodologia de análise do discurso chárgico - que leva em consideração os elementos visuais e o contexto de produção das imagens - analisamos a retratação de situações de violência contra a mulher utilizada em charges que não abordam temas correlatos, como aborto, violência doméstica, estupro, direitos da mulher. Pelo contrário, essa violência é utilizada apenas como um pretexto temático para a construção de uma crítica a respeito de outros temas. Para tanto, partindo do campo da teoria social crítica, explicamos brevemente o contexto da sociedade patriarcal, apresentamos e analisamos algumas charges e discutimos sua relação com o poder simbólico e a violência cultural com o propósito de problematizar esse tipo procedimento que acaba por contribuir com a manutenção de estereótipos e da condição opressiva imposta sobre as mulheres.

\section{O patriarcado e a dominação e exploração das mulheres}

Não podemos pensar na condição feminina sem levar em consideração o sistema pelo qual as mulheres são dominadas e exploradas: o patriarcado. Segundo Heleieth Saffioti, o patriarcado "ancora-se em uma maneira de os homens assegurarem, para si mesmos e para seus dependentes, os meios necessários à produção diária e à reprodução da vida" (Saffioti, 2004: 105). A base desse sistema se dá no controle, pelos homens, da sexualidade e da capacidade reprodutiva das mulheres, bem como de seu trabalho.

A autora deixa explícito que o patriarcado não é apenas uma forma de discriminação econômica, mas que ele também age no controle sobre os corpos femininos por meio do controle da sexualidade e da reprodução:

A base econômica do patriarcado não consiste apenas na intensa discriminação salarial das trabalhadoras, em sua segregação ocupacional e em sua marginalização de importantes papéis econômicos e políticos-deliberativos, mas também no controle de sua sexualidadee, por conseguinte, de sua capacidade reprodutiva. Seja para induzir as mulheres a ter grande número de filhos, seja para convencê-las a controlar a quantidade de nascimentos e o espaço de tempo entre os filhos, o controle sempre está em mãos masculinas, embora elementos femininos possam intermediar e mesmo implementar estes projetos (Saffioti, 2004: 106).

Assim, de acordo com a autora, o patriarcado consiste em um sistema de dominação - observado nos campos político e ideológico - e exploração - observado no campo econômico (Saffioti, 1987). Esse sistema de desigualdade moldado histórica e socialmente a partir da diferença entre os sexos atua no sentido de determinar os papéis e comportamentos que se espera de homens e mulheres: 
A identidade da mulher, assim como a do homem, é construída através da atribuição de distintos papéis, que a sociedade espera ver cumpridos pelas diferentes categorias de sexo. A sociedade delimita, com bastante precisão, os campos em que pode operar a mulher, da mesma forma como escolhe os terrenos em que pode atuar o homem (Saffioti, 1987: 8).

Aos homens são conferidos papéis de alto valor social, ligados à produção da vida social. Já às mulheres, são designados papéis desvalorizados e invisíveis, ligados à reprodução da vida. Conforme nos aponta Maria de Jesus Izquierdo (1992), as mulheres são destinadas aos papéis de sobrevivência enquanto os homens são destinados aos papéis de transcendência. Isso significa que às mulheres são designados os papéis ligados ao ambiente doméstico e familiar - à esfera da sobrevivência. Ao mesmo tempo, são mantidas longe da esfera pública/de transcendência, na qual as decisões são tomadas. Já aos homens, são destinados papéis que transcendem a sobrevivência; a eles são permitidos pensar o mundo e as relações, a decidir, elaborar leis e padrões etc.

Esse padrão também é observado na inserção das mulheres no mundo do trabalho remunerado. Conforme nos apontam as teóricas da divisão sexual do trabalho (Kergoat, 2010) as mulheres desempenham funções ligadas ao que socialmente é construído como feminino também no ambiente de trabalho, e, mesmo que essas se insiram em atividades ditas masculinas, serão submetidas ao jugo e autoridade dos homens.

Portanto, a desigualdade entre homens e mulheres não é derivada de diferenças biológicas, mas da construção social que conferiu, historicamente, significado às diferenças entre os sexos. A diferença entre os sexos foi transformada na inferioridade socialmente construída das mulheres - o segundo sexo, conforme nos aponta Simone de Beauvoir (2009) - originando o sistema de dominação-exploração imposto pelos homens.

O patriarcado conferiu significado à diferença entre os sexos de modo a construir histórica e socialmente a desigualdade entre eles, utilizando da biologia feminina para justificar sua sujeição ao masculino. O corpo feminino é utilizado não apenas como justificativa para esse sistema como também é explorado para mantêlo: a sexualidade e reprodução da mulher são pontos chave para o patriarcado. De acordo com Saffioti,

Neste regime [patriarcado], as mulheres são objetos da satisfação sexual dos homens, reprodutoras de herdeiros, de força de trabalho e novas reprodutoras. Diferentemente dos homens como categoria social, a sujeição das mulheres, também como grupo, envolve prestação de serviços sexuais a seus dominadores. Esta 
soma/mescla de exploração e dominação é aqui entendida como opressão. (Saffioti, 2004: 105).

Nesse sentido, podemos observar no patriarcado a origem do controle masculino sobre a sexualidade e a reprodução. Apesar de defender uma perspectiva do conhecimento diferente das feministas materialistas mencionadas, Pierre Bourdieu (1998) nos aponta aspectos interessantes sobre a desigualdade entre homens e mulheres. Segundo ele, o sexo é estabelecido pelo masculino que, a partir do momento em que descobre sua função na concepção, se coloca como centro da sexualidade e da reprodução: o falo que cresce e faz crescer o ventre (Bourdieu, 1998: 20). Portanto, o sexo é dado por relações de dominação entre homens e mulheres, relações de poder nas quais as mulheres são submetidas ao jugo dos homens.

Colette Guillaumin (2014) defende que as relações sociais que vivenciamos se utilizam uma suposta "natureza feminina" para justificar a dominação-exploração das mulheres. A sexagem, segundo a autora, revela a apropriação das mulheres por meio de sua transformação da no próprio sexo, em um estado de "coisa" e não de ser humano.

A partir daí, já podemos fazer uma aproximação à violência sexual como forma de controle masculino sobre as mulheres. Se o sexo, que é estabelecido pelo masculino e está a serviço do prazer dos homens, e, ao mesmo tempo, é baseado no poder que um sexo tem sobre o outro - o masculino sobre o feminino - então, as relações de poder são reforçadas e demonstradas pelo domínio sexual, que tem como seu maior expoente o estupro de homens contra mulheres.

Conforme nos traz Saffioti (1987: 29), “a construção social da supremacia masculina exige a construção social da subordinação feminina”. Assim, a manutenção do poder masculino passa pela construção e reforço da subordinação feminina - o que é latente quando observada a violência sexual contra mulheres institucionalizada em nossa sociedade.

Ao mesmo tempo, quando observados o papel conferido às mulheres, percebemos que a resignação é esperada das mulheres até mesmo quando estas são abusadas ou traídas: "na qualidade de vítima, de sofredora, de quem aceita, sem reclamar, seu destino de mulher, merece aplausos por parte da sociedade" (Saffioti, 1987: 35).

A leitura de Carole Pateman (1993) nos ilumina acerca da questão quando a autora analisa a propriedade sexual dos homens sobre as mulheres subentendida nas relações entre os sexos. Em suas reflexões Pateman mostra como o controle masculino sobre a sexualidade das mulheres foi historicamente legitimado pela "ciência" e pelos grandes pensadores, como Rousseau, Kant, Hegel etc. que contribuíram na construção dos estereótipos femininos ligados à irracionalidade, à imoralidade e à incapacidade intelectual.

Jean Jacques Rousseau, por exemplo, considerado um dos grandes filósofos do Iluminismo, contribuiu (e ainda contribui) para a permanência das mulheres na 
condição oprimida ao defender que a educação dos homens deve ser diferente da educação das mulheres, e que estas devem apenas ser educadas para que agradem aos homens, conforme nos traz os apontamentos de Bárbara Nogueira (2016). Partindo do essencialismo biológico e defendendo a irracionalidade inata das mulheres, Rousseau define um modelo ideal de mulher que permanece até hoje - baseado nos mesmos princípios e argumentos - no imaginário da sociedade.

É notável que as relações de dominação permeiam todas as instâncias da vida social. Elas se encontram entranhadas nas instituições sociais, que naturalizam os papéis socialmente construídos dos dois sexos e reproduzem a hierarquia proveniente dessa dominação em todos os âmbitos da ordem social. De acordo com Bourdieu, as estruturas de dominação:

[...] são produto de um trabalho incessante (e, como tal, histórico) de reprodução, para o qual contribuem agentes específicos (entre os quais os homens, com suas armas como a violência física e a violência simbólica) e instituições, famílias, Igreja, Escola, Estado (Bourdieu, 1998: 46).

Portanto, a hierarquia sexual está presente também de forma simbólica - o que, para as mulheres, não é menor ou maior do que as outras formas. Como nos aponta Nancy Fraser (2015), o simbólico e o cultural são tão materiais quanto as determinações econômicas ou políticas. Compreendemos que a ordem simbólica decorre das estruturas da sociedade em que vivenciamos: patriarcal, racista e capitalista, assim como as sustenta. Nesse sentido, a violência simbólica se apresenta como uma imposição de sentidos por meio do discurso, que reforça uma estrutura material de opressão às mulheres.

Demonstrar as origens da violência contra as mulheres é essencial para combater a visão que compreende a dominação masculina como natural. Segundo Soihet (2008), as relações de dominação são, ao mesmo tempo, construídas em um tempo histórico, cultural e discursivo, e não natural, universal e instransponível. Para superar a dominação que se mostra concreta na vida cotidiana, a autora explica que "é preciso transformar profundamente as disposições adquiridas por uma espécie de reeducação - aquela que é necessária para perder um mau costume - é preciso, portanto, mudar a ordem simbólica." (Soihet, 2008: 204-205).

\section{Violência contra a mulher em charges e cartuns}

Tendo compreendido brevemente alguns dos pontos centrais que determinam a opressão da mulher na sociedade e, sobretudo, o papel do controle sexual nesse contexto, partimos para a apresentação e análise de algumas charges que exploram situações de violência contra as mulheres como argumento visual para, então, 
discutir o potencial simbólico da reprodução da exploração e da dominação feminina em imagens.

A primeira charge apresentada nos traz a figura de uma estátua da deusa Têmis, símbolo da Justiça, machucada e ensanguentada, com a roupa rasgada e seus pertences jogados ao chão, com uma feição revoltada, dentes à mostra e boca aberta como se estivesse gritando (figura 1). Como se a imagem por si só não fosse suficiente para entendermos que a figura feminina havia sido violentada, no alto da charge lemos os dizeres "sequestrada, torturada, estuprada".

É recorrente encontrarmos charges que retratam a Justiça em sua forma feminina da deusa Têmis, denunciando e/ou criticando injustiças por meio da representação da violência contra a mulher. A Justiça, quando representada em figuras femininas nas charges, é invariavelmente colocada nas situações mais perversas para as mulheres: violência moral, física e estupro. A recorrência desse tipo de representação demonstra a naturalização da violência contra a mulher principalmente, a sexual - ao utilizá-la como pretexto para qualquer tipo de crítica; não importa qual o assunto, se a Justiça é representada por uma deusa mulher, a crítica será demonstrada colocando a sua figura em uma situação de violência. Sendo o estupro uma das mais humilhantes violências e a demonstração maior da submissão das mulheres aos homens, este é intensamente utilizando para representar críticas quando as figuras são femininas.

Figura 1 - Sequestrada, torturada e estuprada

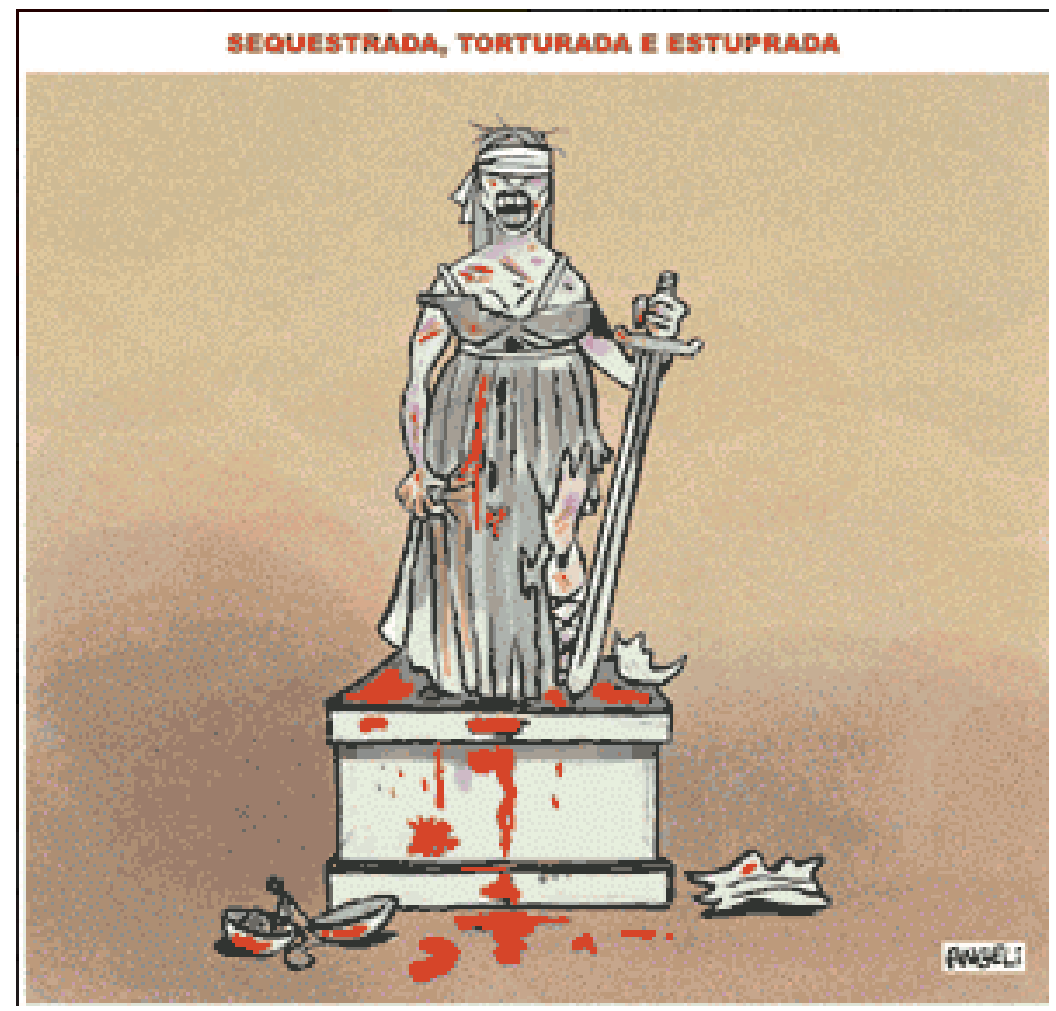

Fonte: Folha de S. Paulo, $2010^{2}$. Charge de Angeli.

2 Edição do dia 03 de maio de 2010. Disponível em: <http://acervo.folha.uol.com.br/fsp/2010/05/03/2>. 
A recorrência desse tipo de argumento visual que coloca a deusa Têmis violentada como crítica à injustiça reforça a alegação sobre a naturalização da violência e dos papéis submissos das mulheres, além de demonstrar a obviedade desse tipo de representação e, ainda, revela a dificuldade que os chargistas encontram em fugir de imagens misóginas em críticas políticas, sobretudo, em se tratando de uma instituição representada por uma figura feminina.

Na charge a seguir, a deusa Têmis é novamente utilizada para representar a Justiça. Dessa vez, retratada em forma de mulher, Têmis usa roupas curtas e está localizada em uma esquina - segundo o cartunista, "Esquina Brasil" - insinuando uma situação de prostituição (figura 2). Ela é segurada pelo braço pelo então ministro do Supremo Tribunal Federal (STF), Gilmar Mendes, e cercado por dois “jagunços”, afirmando para a figura feminina "Destruir como?? Se eu cuido tão bem de você?!". Acima, localizamos os dizeres "O ministro Joaquim Barbosa afirmou que Gilmar Mendes está destruindo a Justiça no Brasil...”. A charge foi publicada em 2009 no contexto de uma discussão entre Joaquim Barbosa e Gilmar Mendes, na qual o primeiro criticou as declarações na mídia feitas pelo segundo.

Nessa charge a violência masculina contra as mulheres é utilizada como pretexto temático para fazer críticas políticas a um debate público envolvendo dois magistrados brasileiros. Uma referência à mercantilização e à exploração dos corpos femininos foi utilizada para criticar como a Justiça é conduzida e tratada no país. Parte-se da ideia de que os corpos das mulheres estão disponíveis para o bel prazer dos homens. É notável também a ideia da dupla moralidade imposta às mulheres, dividindo-as entre "santas" e "putas", confiáveis e não confiáveis, imorais e incapazes de racionalidade. 
Figura 2 - Gilmar Mendes e a Justiça

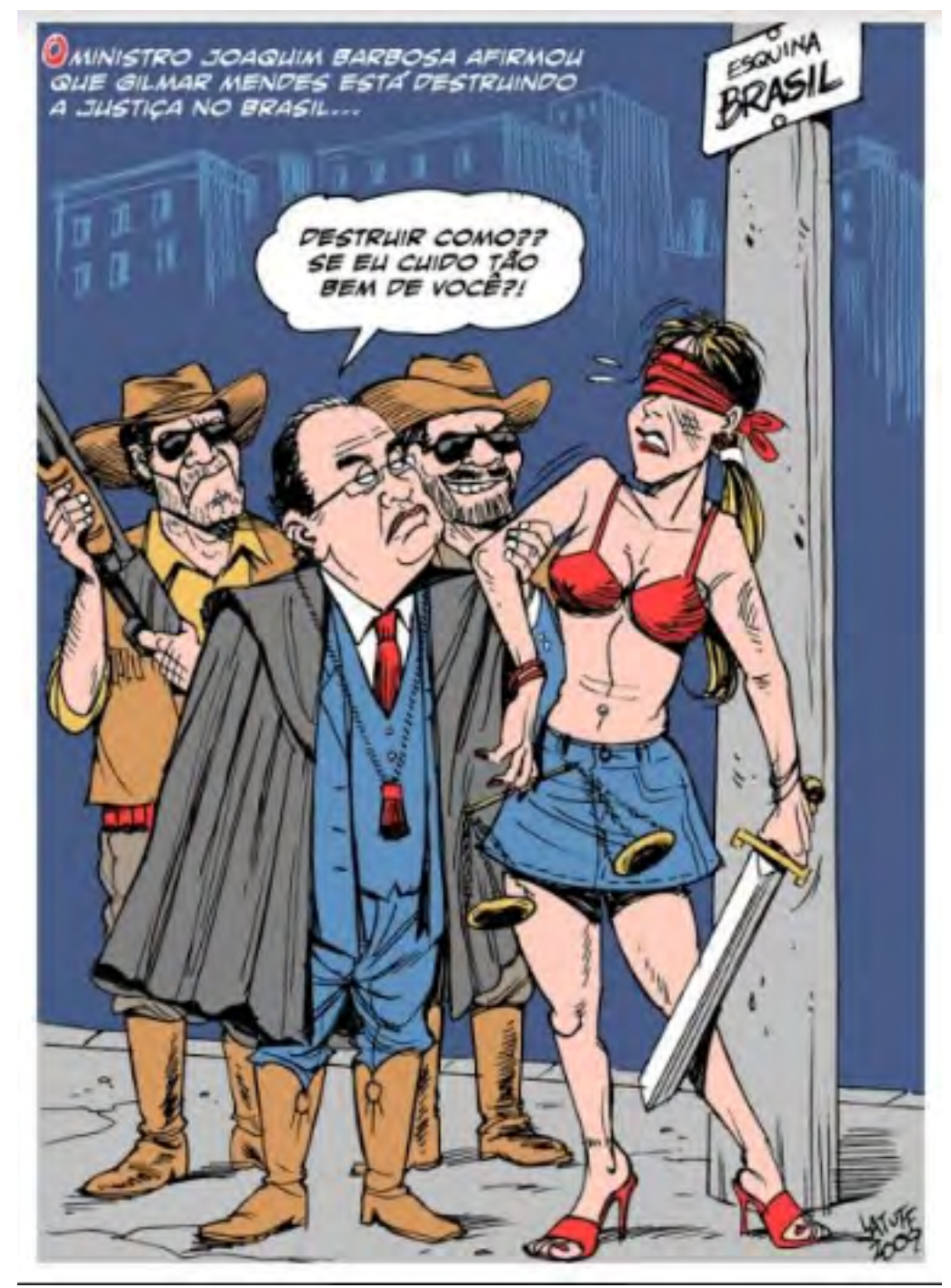

Fonte: Acervo do chargista, 2009. Charge de Latuff.

A presença de Gilmar Mendes segurando violentamente a "Justiça prostituída” em uma esquina, dizendo que "cuida bem dela", nos remete aos cafetões que exploram o corpo das mulheres e demonstra, com latência, a dominação dos homens sobre as mulheres. Enquanto a vida das prostitutas está nas mãos dos cafetões, a vida da Justiça está nas mãos de Mendes; logo, a vida das mulheres está nas mãos dos homens. Enfim, a charge demarca bem quais são os papéis dos sexos: aos homens, o poder, as decisões, a política; às mulheres, a servidão política, doméstica, sexual.

A próxima charge, produzida no contexto das eleições presidenciais de 2010 - publicada inicialmente no site do chargista e depois reproduzida no blog da Folha de S.Paulo na coluna de Josias de Souza - apresenta a então candidata do Partido dos Trabalhadores (PT) à Presidência da República, Dilma Rousseff, retratada como prostituta (figura 3). Fazendo ponto em uma esquina, "rodando bolsinha", Dilma aparece dizendo "O programa quem faz são os fregueses: PMDB: barba, cabelo e bigode; PDT: papai e mamãe. E por aí vai...”. 


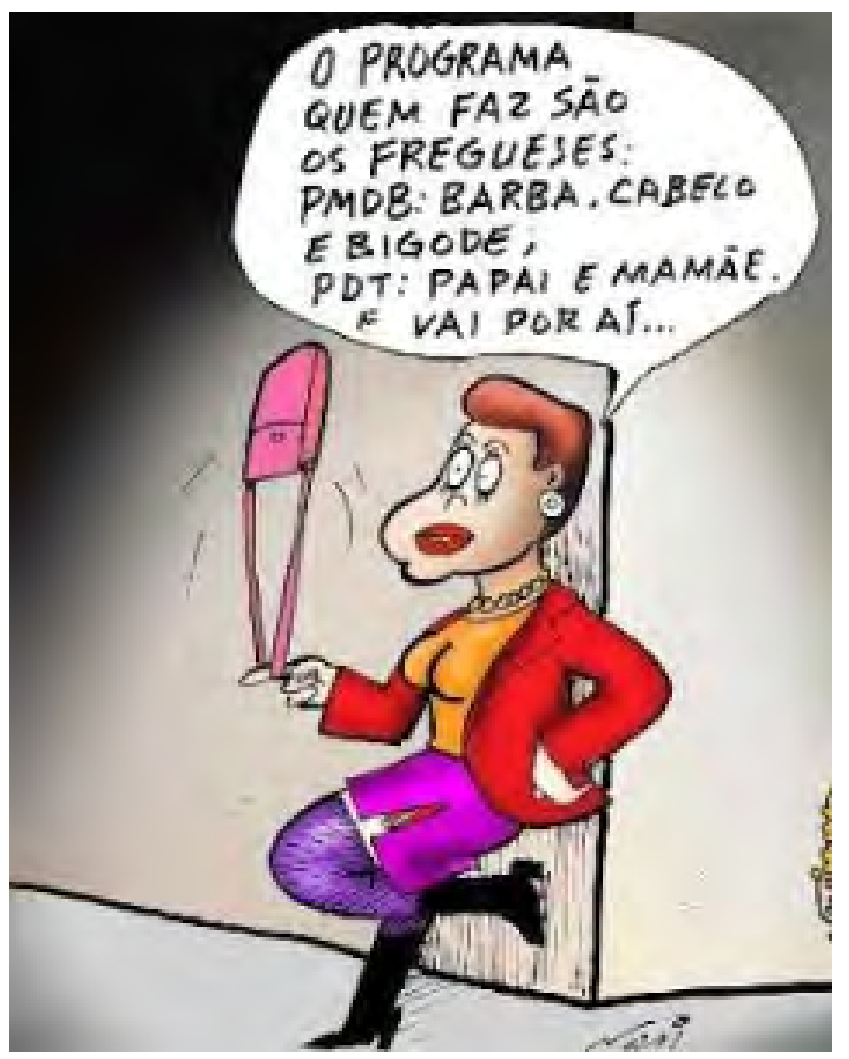

Fonte: Nani Humor, $2 \mathrm{OlO}^{3}$. Charge de Nani.

Essa imagem nos remete a reflexões sobre os papéis sociais impostos às mulheres. Quando, pela primeira vez na história do país, uma mulher é a favorita para vencer as eleições presidenciais e ocupar o cargo de presidenta, utiliza-se de imagens depreciativas para retratá-la. Além disso, a charge sugere que não é Dilma quem escolhe seu programa, que esta é utilizada pelos outros partidos - representados por homens. Esse tipo de crítica se utiliza dos estereótipos da dupla moralidade imposta às mulheres, nesse caso para criticar o programa político da candidata Dilma.

É interessante notar que quando a crítica é direcionada às mulheres estas são colocadas em papéis que conotam a submissão aos homens, bem como reforçam os estereótipos de incapacidade racional, imoralidade, desonestidade - que se pode notar na referida charge ao retratar Dilma como o que a sociedade considera a escória: uma prostituta. A mercantilização do corpo das mulheres a serviço do prazer dos homens, por si só, já é uma violência; tenta-se naturalizar a ideia de que os corpos das mulheres estão disponíveis aos homens. E essa violência é utilizada de maneira simbólica para deslegitimar as mulheres e afirmar a histórica submissão aos homens. Em síntese, a charge sugere que Dilma não é capaz de governar, que é apenas uma "prostituta" que "se vende" para outros políticos, e que estes a tem ao seu dispor.

3 Site do autor: Disponível em: <http://www.nanihumor.com/2010/o7/programa-de-dilma-depende-dos-partidos. html>. Reproduzida no blog da Folha de S. Paulo. Disponível em: <http://josiasdesouza.folha.blog.uol.com.br/ arch2010-07-01_2010-07-31.html\#2010_07-08_02_26_31-10045644-0>. 
Não obstante, a charge a seguir demonstra que, mesmo quando a crítica não é direcionada a uma mulher, mulheres são utilizadas nas imagens em situações de subserviência. Produzida por Vitor Teixeira, a charge remete à entrevista com Marcela Temer - esposa do então vice-presidente Michel Temer -, publicada em abril de 2016 pela revista Veja, cerca de três meses antes do golpe (figura 4). O título da matéria definia Marcela como bela, recatada e "do lar".

Figura 4 - Bela, recatada e do lar

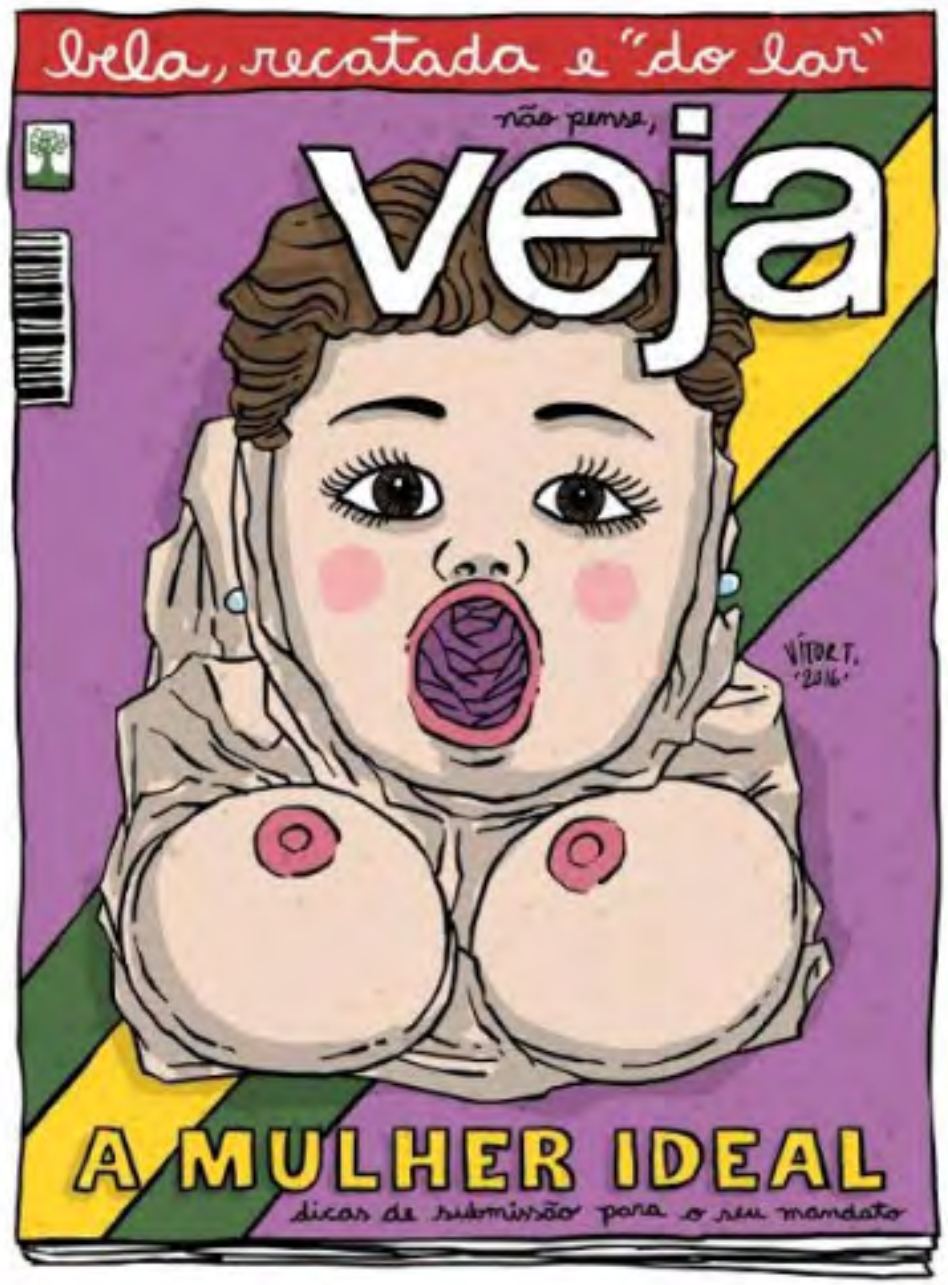

Fonte: Brasil de Fato, $2016^{4}$. Charge de Vitor Teixeira.

Os elementos visuais nos permitem afirmar que o chargista tem uma posição crítica com relação à entrevista, que sugere papéis de submissão à mulher e o fortalecimento de um ideal feminino voltado ao ambiente doméstico, à delicadeza, também instrumentos de controle das mulheres na sociedade. No entanto, ao construir sua crítica voltada ao contexto político e à publicação da entrevista, Vitor Teixeira utiliza um retrato caricato da presidenta Dilma Rousseff com as características de uma boneca inflável.

4 Disponível em: <https://www.brasildefato.com.br/2016/05/05/vitor-teixeira-meu-trabalho-nao-e-resposta-denada-e-pergunta/>. 
Aqui vale fazer uma relação com a pesquisa de Soihet (2005) que analisou charges publicadas no jornal O Pasquim, jornal alternativo da época da ditadura militar brasileira que usava da ridicularização para fazer críticas ao regime. Mesmo com uma perspectiva crítica e libertária, assumia "uma postura misógina, voltando sua mordacidade, igualmente, para as mulheres que se decidiram pela luta com vistas a atingir direitos e/ou que no seu cotidiano assumiam atitudes consideradas como inadequadas à feminilidade e às relações estabelecidas entre os gêneros" (Soihet, 2005: 594). Em sua análise, a autora identificou que as charges retratavam mulheres utilizando estereótipos negativos, como a feiura, a inconsequência, menor inteligência, entre outros.

Fazemos esse paralelo aqui para destacar que a posição editorial do veículo de comunicação, ou mesmo a posição política do chargista, não foram suficientes para transpor uma estrutura patriarcal e misógina, mesmo que no âmbito simbólico. Portanto, mesmo que a crítica seja direcionada à revista Veja e ao modelo ideal de mulher e, mesmo, de feminilidade, o recurso utilizado é a representação de Dilma Rousseff como uma boneca inflável, a materialização da ideia de mulheres como objetos sexuais. Ideia essa que compõe o repertório comum de conhecimento na sociedade patriarcal. Ou seja, ao invés de transgredir essa representação, o chargista se apropria dela e a reproduz para satirizar o acontecimento.

O desenho sugere que, na visão da revista Veja, a "mulher ideal" seria útil para o sexo. No entanto, por mais que desenvolva uma crítica a essa postura machista, os elementos visuais evidenciam a escolha por colocar a figura de uma líder política em uma situação humilhante. Ao fazer a crítica, lança mão de referências misóginas, demonstrando como o repertório do imaginário social é povoado por imagens de violência contra a mulher. Nesse sentido, é preciso questionar até que ponto imagens como essa - que constituem críticas ao sistema patriarcal - contribuem para a legitimação e confirmação do mesmo sistema, ao invés de propor novas imagens que colaborem para sua superação.

Até então, vimos exemplos de charges que utilizaram a violência contra a mulher para fazer críticas a uma instituição representada por uma mulher - a deusa Têmis como a Justiça e charges que envolviam a presidenta Dilma Rousseff. Essa observação é importante porque havia, de alguma forma, mulheres envolvidas no contexto de produção das críticas. A charge a seguir, de forma mais evidente que as anteriores, oferecia ao chargista uma série de outras possibilidades e caminhos para expressar seu ponto de vista sobre o fato retratado, porém, sua escolha foi por utilizar como pretexto temático uma situação de violência contra a mulher.

Publicada na Folha de S. Paulo em maio de 2016, a charge produzida por Guabiras acompanha o texto de Vladimir Safatle. O contexto de veiculação da charge é de alguns dias após o afastamento da presidenta Dilma Rousseff no processo de "impeachment". Durante esse período, uma das manifestações mais populares dos apoiadores do processo foram os panelaços, em que panelas eram utilizadas para fazer barulho de dentro das casas. O texto indaga sobre o fim das manifestações que se intitulavam contra a corrupção - após o afastamento de Dilma. 
Na charge, vemos uma mulher, com proporções exageradas, vestindo roupas amarelas com detalhes verdes e acessórios como pulseiras e anéis, segurando uma taça de champanhe, o que pode indicar uma determinada classe social. Uma panela com o cabo colocado no ânus da mulher faz a relação com o contexto, já que, de acordo com o texto, as panelas deixaram de ser batidas, uma alusão ao fim repentino das manifestações (figura 5).

Considerando o contexto sociopolítico de produção da charge, bem como a construção discursiva do texto que acompanha a imagem no jornal, podemos afirmar que o único elemento visual necessário para a identificação do momento político seria a panela. A presença da mulher e a forma como os elementos visuais interagem é absolutamente arbitrária e demonstra uma opção deliberada por representar o fim dos panelaços na forma de uma violação do corpo da mulher.

Figura 5 - Paneleiros

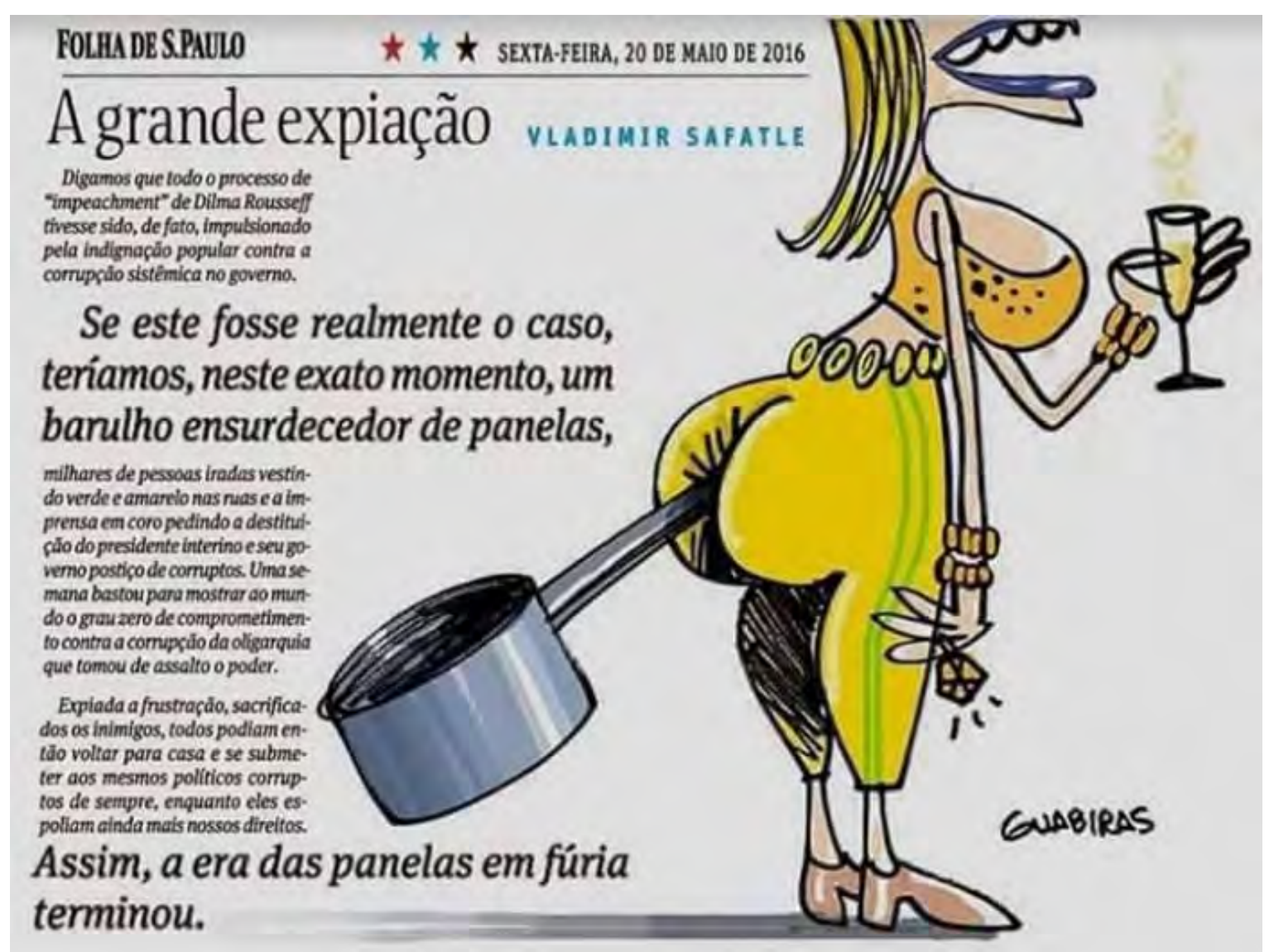

Fonte: Folha de S. Paulo, edição de 20 de maio de 2016.

Da mesma forma, a charge a seguir utiliza a violência contra a mulher para expor um posicionamento sobre a situação da Petrobrás. A charge retrata a campanha "Não mereço ser estuprada" (figura 6), lançada nas redes sociais pela jornalista Nana Queiroz após a divulgação de uma pesquisa do Instituto de Pesquisa Econômica Aplicada (Ipea) que apontava que $65 \%$ das pessoas entrevistadas acreditava que mulheres com roupas curtas mereciam ser estupradas (UOL, 2014). A campanha, 
portanto, estava presente na memória social e poderia ser utilizada para dialogar com os leitores.

Figura 6 - Não mereço ser estuprada

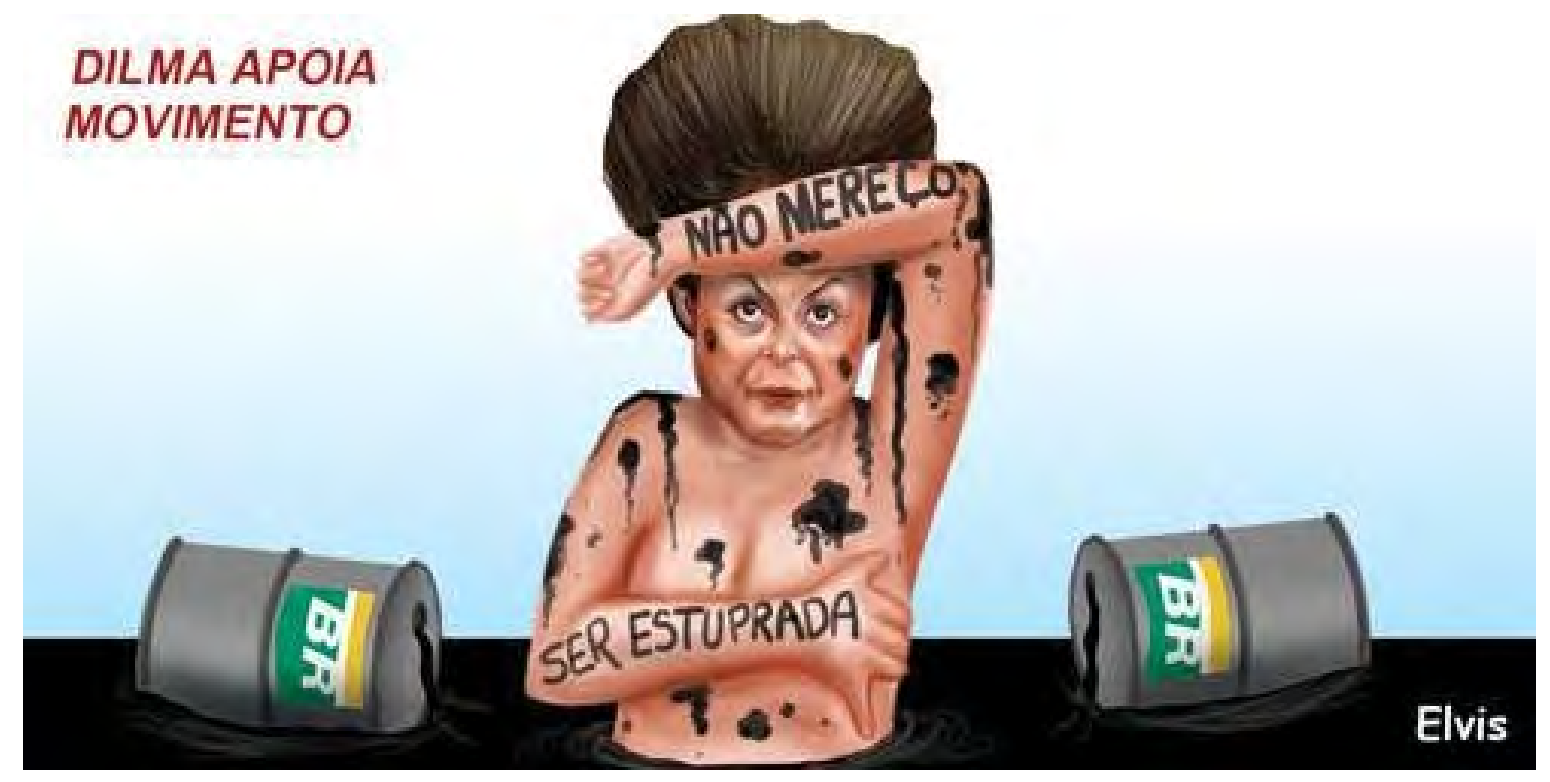

Fonte: Folha de S. Paulo, edição de 20 de maio de 2016.

Essa campanha mobilizou milhares de mulheres por meio da hashtag \#EuNaoMerecoSerEstuprada e consistia na publicação nas redes sociais de uma foto acompanhada da referida frase; a campanha conquistou, inclusive, o apoio da então presidenta Dilma Rousseff. Aproveitando a situação, o chargista se apropriou do contexto da reivindicação em defesa das mulheres para fazer a crítica à situação econômica enfrentada pela Petrobrás. A mulher é representada nua na imagem, em uma posição que demonstra sua vulnerabilidade, já que busca se proteger com os braços. Novamente, a vulnerabilidade física e a exposição do corpo se configuram como elementos centrais na composição do discurso chárgico.

O sentido criado é o de comparar a luta por direitos das mulheres com a necessidade de preservar a empresa estatal. Essa apropriação produziu um efeito de ironizar e deslegitimar a campanha criada pelas mulheres contra o estupro - violência que acomete 125 vítimas por dia, segundo o Anuário Brasileiro de Segurança Pública de 2016. O uso da palavra "estupro", que determina abuso e violência sexual, usada como metáfora, contribui para a banalização e esvaziamento do termo. Sobre isso, Soihet (2005: 609) comenta que

Evidencia-se quealgo aparentemente inofensivo como a zombaria, o deboche, configura-se como forma de violência, inoculando representações com vistas à conservação do status quo, através da ridicularização de movimentos em prol de mudanças com relação aos papéis exercidos por mulheres e homens na sociedade. 
As análises realizadas reafirmam a posição de Rachel Wallace (2018: 131): "charges simultaneamente refletem e perpetuam estereótipos". Refletem os estereótipos, justamente, pela necessidade de recorrer aos fatos, acontecimentos e conhecimentos disponíveis na memória social de um determinado grupo em um determinado tempo para subsidiar a construção do discurso. Na medida em que essa referência é realizada sem uma transgressão da ideia original que é acionada, acaba por perpetuar o estereótipo.

\section{Imagens, comunicação e poder simbólico}

As imagens trazidas para este estudo certamente demonstram que a violência contra a mulher faz parte do imaginário social e, por isso, acaba sendo utilizada como um pretexto temático na produção de charges. No entanto, é preciso refletir sobre as consequências desse uso e pensar como a reprodução dessas imagens pode interferir nas estruturas sociais já que, segundo Bourdieu (1998, p.50), “a força simbólica é uma forma de poder que se exerce sobre os corpos, diretamente, e como que por magia, sem qualquer coação física”.

Para colaborar com essa reflexão, apresentamos aqui a contribuição de Johan Galtung (1989), precursor dos estudos para a paz, que diferencia três tipos de violência. A primeira delas, em que se pode ver mais nitidamente a relação sujeitoação-objeto, é a violência direta. Nela, é possível perceber com clareza quem é o ator e quem é a vítima da violência, em situações concretas e observáveis. O segundo tipo é a violência estrutural, um fenômeno invisível, em que se percebem as vítimas, mas não os atores da violência, que acontece por meio da estrutura social, como machismo, racismo ou violência política.

Certamente mulheres vivem situações muito variadas de violência direta, como o estupro, a violência doméstica e até mesmo psicológica, assim como a violência estrutural, como a privação dos espaços públicos, subrepresentatividade política, diferença salarial, entre tantos outros. No entanto, nos interessa aqui tratar da violência cultural (Galtung, 1989) que, para o autor, é aquela que legitima e valida as outras formas de violência.

Educação, ciência, meios de comunicação, arte, religião contribuem para a formação de valores e ideias na sociedade, ou seja, participam ativamente da construção da realidade social. Uma relação possível entre os tipos de violência é a cultura ensinar e preparar para a aceitação da exploração como natural, podendo a violência direta ser utilizada para viabilizar essa exploração.

Podemos associar essa relação - já que as mulheres se deparam com o controle masculino por meio da violência sexual - não apenas quando a violência é física, mas quando observamos qualquer coação - mesmo que simbólica - que reproduza os papéis de resignação, aceitação, medo e ameaça às mulheres e, ao mesmo tempo, poder, virilidade e força aos homens. Como exemplo, temos xingamentos e ditados 
populares, bem como representações na mídia das mulheres como objeto, disponíveis ao prazer masculino. Assim, podemos concluir que as formas simbólicas também reforçam a violência sexual como forma de controle dos homens sobre as mulheres.

Os homens, segundo Bourdieu (1998), são os "detentores do monopólio dos instrumentos de produção e reprodução do capital simbólico" e, portanto, "visam assegurar a conservação ou o aumento deste capital". Para isso, se utilizam de estratégias, dentre as quais, o domínio sexual, "todas elas orientadas no sentido de transmissão dos poderes e dos privilégios herdados" (Bourdieu, 1998: 62). Sendo assim, o controle sexual masculino é mais uma das estratégias do patriarcado para se manter enquanto sistema de dominação-exploração.

Por esse motivo é tão difícil que as mulheres saiam da condição de subalternidade, já que, além desta condição estar naturalizada em todas as instâncias sociais, ela é construída por aqueles que estão no domínio. Assim, por estarem no domínio, utilizam de mecanismos políticos, sociais, econômicos e culturais para manter afastadas das esferas de decisão as mulheres, perpetuando essa condição entre as categorias subalternas.

Nesse sentido, propomos o necessário questionamento à massiva presença do uso da violência sexual como pretexto temático e argumento visual para as críticas políticas contidas em charges. Por qual motivo a referência ao estupro e à violência contra as mulheres (ou instituições representadas pelo feminino) é tão utilizada quando se quer retratar "criticamente" um fato político? Mais do que isso, não obstante a posição ideológica, origem de classe ou raça/etnia: por que a violência sexual contra mulheres é utilizada de maneira recorrente como recurso para qualquer crítica que seja?

\section{Considerações finais}

A violência contra a mulher é utilizada como um pretexto temático em charges porque compõe o imaginário social. Dependem da compreensão do leitor sobre fatos históricos ou aspectos culturais para que a mensagem faça sentido e, mergulhados nessa mesma realidade, os chargistas reproduzem imagens de mulheres vítimas de violência, deslocando-as para outros contextos.

Sabemos que essas imagens são alimentadas por estruturas, relações, instituições. Podemos dizer que as imagens produzidas pelos chargistas são produto de uma realidade e de um imaginário coletivamente construído. No entanto, enfatizamos que esse imaginário, que nossa cultura, que as relações de poder são cotidianamente reconstruídas, ressignificadas ou reafirmadas.

Enquanto o imaginário interfere na criação de imagens, as imagens criadas contribuem para a formação do imaginário. É preciso optar por continuar esse ciclo, reproduzindo imagens que já estão estabelecidas, como as de violência contra 
a mulher, ou criar uma ruptura, propondo novos sentidos e novas perspectivas, pautados em mulheres livres de opressão de classe, gênero e raça/etnia.

Destacamos também o papel central das mulheres enquanto coletivo na denúncia das violências cotidianas, quaisquer que sejam os tipos, bem como na reivindicação da liberdade, autonomia e dignidade das mulheres. Afinal, como afirmou Saffioti, os homens (não obstante a classe social e grupo racial/étnico a que pertencem) não abrirão mão espontaneamente dos privilégios que têm, uma vez que "o poder está concentrado em mãos masculinas há milênios. E os homens temem perder privilégios que asseguram sua supremacia sobre as mulheres" (Saffioti, 1987, p.16). Por isso, a resistência das mulheres também está na recusa das representações misóginas do "segundo sexo" nas charges e cartuns.

\section{Referências Bibliográficas}

BEAUVOIR, Simone de. (2009). O segundo sexo. 2. ed.. Rio de Janeiro: Nova Fronteira.

BOURDIEU, Pierre. (1998). A dominação masculina. Rio de Janeiro: Bertran do Brasil.

FRASER, Nancy. (2015). Fortunas del feminismo: del capitalismo gestionado por el Estado a la crisis neoliberal. Espanha: Traficantes de sueños.

GALTUNG, Johan. (1989). Violência cultural. Gernika Gogoratuz.

GUILLAUMIN, Colette. (2014). "Prática do poder e ideia de natureza”. In: FERREIRA, Veronica; ÁVILA, Maria Betânia; FALQUET, Jules; ABREU, Maira (orgs). O patriarcado desvendado: teoria de três feministas materialistas. Recife: SOS Corpo.

IZQUIERDO, Maria de Jesus. (1992). Bases materiais del sistema sexo/gênero. São Paulo: SOF.

KERGOAT, Danielle. (200o). "Divisão sexual do trabalho e relações sociais de sexo". Dictionnaire critique du féminisme. Paris: Presses Universitaires de France.

MIANI, Rozinaldo Antonio. (2012). "Charge: uma prática discursiva e ideológica”. Revista Nona Arte, São Paulo, v. 1, n. 1, p. 37-48, 1o semestre.

MIANI, Rozinaldo Antonio. (2005). As transformações no mundo do trabalho na década de 1990: o olhar atento da charge na imprensa do Sindicato dos Metalúrgicos do ABC paulista. Tese (Doutorado em História). Faculdade de Ciências e Letras de Assis, Universidade Estadual Paulista, Assis, impresso. 
MOORE, A. (2012). "Buster Brown at the Barricades". In: Diversos. Occupy Comics. Black Mask.

NOGUEIRA, Bárbara Weinert Ferreira. (2016). "A contribuição de Rousseau para a desigualdade de gênero". In: Simpósio de Gênero e Políticas Públicas, 4. ed., Londrina. Anais do IV Simpósio de Gênero e Políticas Públicas. Universidade Estadual de Londrina, 2016. Disponível em: <http://www.uel.br/eventos/gpp/pages/arquivos/ GT8_Barbara \% 2oWeinert\%2oFerreira\%2oNogueira.pdf>. Acesso em: 13 mar. 2017.

PATEMAN, Carole. (1993). O contrato sexual. Rio de Janeiro: Paz e Terra.

SAFFIOTI, Heleieth. (2004). Gênero, patriarcado e violência. São Paulo: Editora Fundação Perseu Abramo.

SAFFIOTI, Heleieth. (1987) O poder do macho. São Paulo: Editora Moderna.

SOIHET, Rachel. (2005). "Zombaria como arma antifeminista antifeminista: instrumento conservador entre libertários”. Estudos Feministas, Florianópolis, v. 3, n. 13, p. 591-611, setembro-dezembro.

SOIHET, Rachel. (2008). "Mulheres investindo contra o feminismo: resguardando privilégios ou manifestação deviolência simbólica?”. Estudos de Sociologia, Araraquara, v.13, n.24, p.191-207.

WALLACE, Rachel. (2018). “'She’s Punch Drunk!!': Humor, Domestic Violence, and the British Working Class in Andy Capp Cartoons, 1957-1965." Journal of Popular Culture, vol. 51, n. 1, p. 129-151.

Recebido: 03.08.2018

Aceito: 22.10.2018 